This manuscript has been accepted for publication in Personality and Individual Differences

\title{
Fearing the Disease or the Vaccine: The Case of COVID-19
}

6 Karlsson $^{5}$, Saara Nolvi ${ }^{6}$, Max Karukivi ${ }^{7}$, Mikael Lindfelt ${ }^{8}$, and Jan Antfolk ${ }^{9}$

${ }^{1}$ Department of Psychology, Åbo Akademi University, Finland; linda.karlsson@abo.fi

${ }^{2}$ FinnBrain Birth Cohort Study, Institute of Clinical Medicine, University of Turku, Finland; anna.soveri@utu.fi

${ }^{3}$ School of Psychological Science, University of Bristol, United Kingdom; and School of

Psychological Science, University of Western Australia, Australia;

stephan.lewandowsky@bristol.ac.uk

${ }^{4}$ FinnBrain Birth Cohort Study, Institute of Clinical Medicine, University of Turku, Finland;

17 the Centre for Population Health Research, University of Turku and Turku University

Hospital, Finland; and Department of Child Psychiatry, Turku University Hospital and

University of Turku, Finland; linnea.karlsson@utu.fi

${ }^{5}$ FinnBrain Birth Cohort Study, Institute of Clinical Medicine, University of Turku, Finland; and Centre for Population Health Research, University of Turku and Turku University Hospital, Finland; and Department of Psychiatry, Turku University Hospital and University of Turku, Finland; hasse.karlsson@utu.fi ${ }^{6}$ FinnBrain Birth Cohort Study, Institute of Clinical Medicine, University of Turku, Finland; Turku Institute for Advanced Studies, Department of Psychology and Speech-Language 
1 Pathology, University of Turku, Finland; and Department of Medical Psychology, Charité

2 Universitätsmedizin Berlin, Corporate Member of Freie Universität Berlin, Humboldt-

$3 \quad$ Universität zu Berlin, Germany; saara.nolvi@utu.fi

$4 \quad{ }^{7}$ FinnBrain Birth Cohort Study, Institute of Clinical Medicine, University of Turku, Finland;

5 and Department of Psychiatry, Turku University Hospital and University of Turku, Finland;

6 max.karukivi@utu.fi

$7 \quad{ }^{8}$ Department of Theological Ethics, Åbo Akademi University, Finland;

8 mikael.lindfelt@abo.fi

$99{ }^{9}$ Department of Psychology, Åbo Akademi Univerity, Finland; jan.antfolk@abo.fi

10 http://creativecommons.org/licenses/by-nc-nd/4.0/

Declarations of interest: none number: +358408244119 polininstitutet.fi/en/polin-institute/).

*Address correspondence to Linda C. Karlsson, Department of Psychology, Åbo Akademi University, Tehtaankatu 2, 20500, Turku, Finland, e-mail: linda.karlsson@abo.fi, phone

Funding: LCK was funded by the doctoral network of Minority Research (www.abo.fi/en/minority-research/) at Åbo Akademi University. AS was funded by the Academy of Finland (grant number: 316004; www.aka.fi/en/). ML was funded by the Academy of Finland (grant number: 316726; www.aka.fi/en/) and the Polin Institute (www.

(C) 2020. This manuscript version is made available under the CC-BY-NC-ND 4.0 license 27 

perceived risk; perceived vaccine safety

\section{Abstract}

As studies indicate that people perceive COVID-19 as a threatening disease, the demand for a vaccine against the disease could be expected to be high. Vaccine safety concerns might nevertheless outweigh the perceived disease risks when an individual decides whether or not to accept the vaccine. We investigated the role of perceived risk of COVID-19 (i.e., perceived likelihood of infection, perceived disease severity, and disease-related worry) and perceived safety of a prospective vaccine against COVID-19 in predicting intentions to accept a COVID-19 vaccine. Three Finnish samples were surveyed: 825 parents of small children, 205 individuals living in an area with suboptimal vaccination coverage, and 1,325 Facebook users nationwide. As points of reference, we compared the perceptions of COVID19 to those of influenza and measles. COVID-19 was perceived as a threatening diseasemore so than influenza and measles. The strongest predictor of COVID-19 vaccination intentions was trusting the safety of the potential vaccine. Those perceiving COVID-19 as a severe disease were also slightly more intent on taking a COVID-19 vaccine. Informing the public about the safety of a forthcoming COVID-19 vaccine should be the focus for health authorities aiming to achieve a high vaccine uptake. Keywords: COVID-19; coronavirus; vaccination intentions; vaccine hesitancy; 


\section{I INTRODUCTION}

Due to the COVID-19 pandemic, the world faces a novel infectious disease, for which there currently is no treatment or herd immunity. The pandemic poses a serious threat to our health and well-being (WHO, 2020a) and researchers are racing to develop and test vaccines against COVID-19 (Callaway, 2020). When vaccines become available, the success of the vaccination program will depend on the public's acceptance of the vaccines. Recent studies have indicated that whereas the majority report they would accept a future vaccine against COVID-19 (Blanchard-Rohner, Caprettini, Rohner, \& Voth, 2020 [pre-print]; Detoc et al., 2020; Dodd, Cvejic, Bonner, Pickles, \& McCaffery, 2020; Faasse \& Newby, 2020; Malik, McFadden, Elharake, \& Omer, 2020; Murphy et al., 2020 [pre-print]; NeumannBöhme et al., 2020), 6-25\% report they would not (Detoc et al., 2020; Faasse \& Newby, 2020; Murphy et al., 2020 [pre-print]; Neumann-Böhme et al., 2020; The COCONEL Group, 2020; Ward, Alleaume, Peretti-watel, \& the COCONEL Group, 2020). Understanding why people feel hesitant towards a vaccine against COVID-19 is of paramount importance, as this can help health authorities boost vaccine acceptance to limit the spread of the disease.

Research shows that vaccine acceptance is a complex decision-making process influenced by a wide range of factors (for reviews, see e.g., Betsch et al., 2018; Brewer et al., 2017; Larson et al., 2014; Thomson et al., 2016). The present study will explore the role of two of these key factors - the perceived risk of the disease the vaccine protects against and the perceived safety of the vaccine-in people's acceptance of a vaccine against COVID-19.

\subsection{Perceived Risk of Disease}

A key determinant in people's vaccination decisions is the risk they associate with the disease the vaccine protects against (Betsch et al., 2018; Thomson et al., 2016). These risk perceptions are often measured as the perceived likelihood of contracting the disease and the perceived severity of the symptoms (Brewer et al., 2007). Risk perceptions are also generally 
1 considered to have an emotional dimension, including fear and worry (Loewenstein, Weber,

2 Hsee, \& Welch, 2001; Slovic, Finucane, Peters, \& MacGregor, 2004). Research shows that

3 individuals who perceive the risk of contracting a vaccine-preventable disease as low,

4 consider the symptoms of the disease as mild, and worry little about the disease, report less

5 intent to take the vaccines and more often remain unvaccinated (Betsch et al., 2018; Bish,

6 Yardley, Nicoll, \& Michie, 2011; Brewer et al., 2007; Schmid, Rauber, Betsch, Lidolt, \&

7 Denker, 2017; Thomson et al., 2016).

The risks related to the novel corona virus SARS-CoV-2, which causes COVID-19, have been given considerable attention. On March $11^{\text {th }} 2020$, the World Health Organization (WHO) declared the outbreak of COVID-19 a pandemic, calling for nations to take "urgent and aggressive" action (WHO, 2020a). The pandemic is a global health crisis that has been covered extensively by the media, and governments and health authorities have taken extensive measures to control the spread of the disease. Therefore it is not surprising that recent studies show that people experience COVID-19 as a threatening disease (Dryhurst et al., 2020; Faasse \& Newby, 2020; Glöckner, Dorrough, Wingen, \& Dohle, 2020 [pre-print]; Kwok et al., 2020; Park, Ju, Ohs, \& Hinsley, 2020; Wise, Zbozinek, Michelini, Hagan, \& Mobbs, 2020).

Looking at different aspects of perceived risk, studies have generally found that individuals who perceive COVID-19 to pose a greater risk engage more readily in preventive efforts, such as handwashing and social distancing (Dryhurst et al., 2020; Faasse \& Newby, 2020; Harper, Satchell, Fido, \& Latzman, 2020; Wise et al., 2020). Investigating the relationship between risk perceptions and willingness to take a prospective vaccine against COVID-19, Malik et al. (2020) found that US respondents who rated the disease higher on a risk perception index (consisting of several risk measures) more often reported that they would accept a vaccine against COVID-19. Glöckner et al. (2020 [pre-print]) found that in a 
1 German sample, those who perceived their likelihood of becoming infected with COVID-19

2 as high and the health consequences of the disease as severe had higher vaccination

3 intentions. By contrast, at an early stage of the pandemic, Faasse and Newby (2020) found in

4 an Australian sample that perceived infection risk and perceived disease severity were not

5 meaningful predictors of COVID-19 vaccination intentions. Instead, the more the

6 respondents worried about a widespread outbreak of COVID-19 in Australia, the higher their

7 intentions were to take a COVID-19 vaccine. Also in a French sample, respondents who were

8 very worried about contracting COVID-19 were more likely to agree to take a hypothetical

9 COVID-19 vaccine (Ward et al., 2020). Taken together, the available research indicates that

10 individuals who perceive the risk of COVID-19 as higher, report more willingness to take a

11 prospective vaccine against the disease. However, there is disagreement among the studies

12 concerning which risk-perception components are the most relevant.

\subsection{Perceived Vaccine Safety}

Another important factor in a vaccination decision is how safe the individual considers the vaccine to be. Individuals who perceive vaccines as safe are more likely to accept vaccinations (Betsch et al., 2018; MacDonald \& the SAGE Working Group on Vaccine Hesitancy, 2015; Thomson et al., 2016). Because vaccines against COVID-19 are still under development, information about the safety of the vaccines is limited. Research, however, suggests that when there is a lack of information and experience about the safety of a new vaccine, people tend to form their opinions based on attitudes to existing vaccines.

This has been demonstrated for example in studies showing that attitudes to childhood vaccines predict intentions to use a hypothetical vaccine against the Zika virus (Harapan et al., 2019; Ophir \& Jamieson, 2018). Another vaccine that might affect attitudes towards a COVID-19 vaccine is the Pandemrix vaccine. Pandemrix may be particularly relevant because it was implemented during a pandemic of a new infectious disease, the swine flu, 
only a decade ago (2009-2010). The Pandemrix vaccine caused big controversy due to its association with an increased risk of narcolepsy (Sarkanen, Alakuijala, Julkunen, \& Partinen, 2018). In Finland, where the present study was conducted, the connection between narcolepsy and the Pandemrix vaccine received a great deal of media attention and this may have exacerbated vaccine hesitancy, especially related to influenza vaccines. This hesitancy might, in turn, affect the public's trust in the safety of a potential vaccine against COVID-19. Another vaccine that has been subject to controversies and may affect the uptake of a COVID-19 vaccine is the MMR vaccine (against measles, mumps, and rubella). This is because a publication in 1998 falsely suggested a link between the vaccine and autism. Although a large amount of research has since shown that the claim of a link is unsubstantiated, some individuals still have unwarranted fears about the vaccine (L. C. Karlsson et al., 2019; Wang, McKee, Torbica, \& Stuckler, 2019).

Paradoxically, vaccine safety concerns might be especially common when the prevalence of the vaccine-preventable disease is low and when vaccination programs have been successful. In those cases, the disease is not considered a high risk, and the perceived risks of vaccination might outweigh the perceived risks of the disease (Dubé et al., 2013; Karafillakis \& Larson, 2017; MacDonald \& the SAGE Working Group on Vaccine Hesitancy, 2015). On the other hand, if the perceived disease risk is very high, individuals might decide to vaccinate despite vaccine concerns.

\subsection{The Current Study}

The current study includes three separate studies conducted in different samples of adults, which aimed 1) to obtain information on the perceived risk of COVID-19 and trust in the safety of a prospective vaccine against COVID-19 and, 2) to examine if the intention to take a vaccine against COVID-19 is related to the perceived risk of the disease and the perceived safety of the vaccine. As points of reference, the perceived risk of influenza and 
1 measles, as well as the perceived safety of the influenza and measles vaccines were also

2 measured.

To get a broad understanding of the role of perceived disease risk on vaccination

4 intentions, and to cover most of the different aspects measured in previous studies, the

5 following main components of disease-risk perceptions were explored: 1) perceived

6 likelihood of infection, 2) perceived disease severity, and 3) disease-related worry. For

7 perceived severity and worry, risk related to both oneself and others were measured.

Study 1 focused on COVID-19 only. In parents of small children, the study investigated whether the perceived risk of the disease predicted intentions to take a potential COVID-19 vaccine recommended by authorities. As COVID-19 has caused more severe symptoms and higher mortality among older individuals (Centers for Disease Control and Prevention, 2020), age was included as a proxy for objective risk.

In Study 2, beyond replicating Study 1, we also measured the perceived risk of influenza and measles. Additionally, the study examined how willing individuals were to take a test-phase COVID-19 vaccine, and whether this willingness was predicted by disease-risk perceptions. The test-phase vaccine was included to represent a vaccine that is likely perceived as less safe, but where perceived disease risk is held constant (the vaccine also protects against COVID-19). The study was conducted in a sample living in an area with suboptimal uptake of vaccines offered in the national vaccination program.

Study 3 replicated Study 2 but extended the focus on perceived vaccine safety by including a measure on whether the respondents trusted that a prospective COVID-19 vaccine recommended by authorities would be safe. We also measured the perceived safety of the influenza and measles vaccines. Intentions to take vaccines against COVID-19 (i.e., a recommended vaccine and a test-phase vaccine) were predicted by both perceived disease risk and perceived vaccine safety. Study 3 also included an additional measure of objective 
1 disease risk, that is, the prevalence of COVID-19, and investigated whether vaccination

2 intentions were higher among respondents living in a region where COVID-19 was more

3 prevalent than among respondents living in other regions. The study was conducted in a

4 nationwide sample of Facebook users.

$5 \quad$ All studies were carried out during or directly after the first peak of the coronavirus

6 pandemic in Finland. The data collection of Study 1 took place between May $4^{\text {th }}$ and June $7^{\text {th }}$,

7 2020, Study 2 between March $30^{\text {th }}$ and April $12^{\text {th }}, 2020$, and Study 3 between April $3^{\text {rd }}$ and

$817^{\text {th }}, 2020$. During Studies 2 and 3, the highest numbers of new COVID-19 cases of the first

9 pandemic wave ( $\sim 900$ per week) were observed, and the total number of cases more than

10 doubled (Finnish Institute for Health and Welfare, 2020). Measures put in place by the

11 Finnish government at the time included closing of schools, limiting public gatherings to a maximum number of 10 individuals, and prohibiting unnecessary travel to and from Uusimaa - the region with the most rapid increase in COVID-19 prevalence (Finnish

14 Government, 2020a, 2020b). During Study 1, the weekly incidence of COVID-19 decreased 15 from 600 to 145.

Because of the acute nature of the pandemic at the time of data collection, it was hypothesized that individuals would perceive COVID-19 to carry a greater risk compared to influenza and measles. Initial mortality estimates for COVID-19 provided by the WHO were also higher, at around 3.4\%, compared to influenza and measles (mortality rates well under 1\%; (Centers for Disease Control and Prevention, 2019; WHO, 2020b). It was also hypothesized that individuals who perceive the risk of COVID-19 as high (as measured by the three aspects of perceived risk) and trust that a prospective COVID-19 vaccine would be safe have higher intentions to vaccinate against COVID-19. Lastly, because the actual risk increases with age and prevalence of COVID-19, higher age and living in an area with higher COVID-19 prevalence were expected to be associated with higher vaccination intentions. 


\section{GENERAL METHOD}

All data were collected through surveys. The surveys mainly consisted of questions probing topics related to the coronavirus pandemic. The relevant measures, which were developed by the authors, are presented in the following sections.

\section{STUDY 1 METHOD}

\subsection{Respondents and Procedure}

In May 2020, 5103 parents from the FinnBrain Birth Cohort Study (L. Karlsson et al., 2018) were invited to an electronic survey including questions related to the coronavirus pandemic. The parents were asked to participate as they had previously (in 2018) been invited to a survey concerning attitudes to vaccines. The survey was open for five weeks. A total of $856(16.8 \%)$ parents responded, but $31(3.6 \%)$ did not answer the questions relevant for the present study and were excluded. The final sample size was, thus, 825 . The mean age of the sample was $37.9(S D=4.75$, range $=23-55$; see Table $\mathrm{S} 1$ in the online supplemental material for demographics: https://osf.io/krjpn/). Ethical approval for the study was obtained from the Ethics Committee of the Hospital District of Southwest Finland. Respondents gave their informed consent to participate in the electronic survey. They did not receive any compensation for their participation.

\subsection{Measures}

\subsubsection{Perceived Disease Risk}

The questions concerning perceived disease risk are presented in Table 1. We formulated the questions on perceived likelihood and severity of disease following the recommendations by Brewer et al. (2007). The respondents were asked to rate their likelihood of contracting COVID-19 within the upcoming 12 months (perceived likelihood of infection). As previous research has indicated that a 7-point verbal scale for perceived likelihood of infection best predicts vaccination behavior (Weinstein et al., 2007), the 
1 response alternatives ranged from 1-7 $(1=$ virtually non-existent, $2=$ very small, $3=$ small, 4

$2=$ medium sized, $5=$ large, $6=$ very large, $7=$ virtually $100 \%$ ). To measure perceived

3 severity, the respondents were asked how severe they expected COVID-19 to be for their own

4 health (perceived personal severity) and how severe of a disease they perceived COVID-19 to

5 be in general (perceived general severity). The respondents answered on a scale from 1-5 (1

$6=$ not severe at all, $2=$ somewhat severe, $3=$ quite severe, $4=$ severe, $5=$ very severe $)$.

7 Lastly, how much respondents worried about falling ill with or transmitting COVID-19 to

8 someone else was measured on a scale from 1-5 (1= not at all, $2=$ somewhat, $3=$ quite

$9 \quad$ much, $4=$ much, 5 = very much). 


\section{Table 1}

\section{Survey Questions Related to Perceived Disease Risk}

\begin{tabular}{|c|c|c|}
\hline Measure & Survey question & Study \\
\hline \multicolumn{3}{|l|}{ COVID-19 } \\
\hline Perceived likelihood of infection & I think that my likelihood of contracting COVID-19 during the following 12 months is ${ }^{\mathrm{a}}$ & All \\
\hline Perceived severity: Personal & How severe would it be for your health if you contracted COVID-19? & All \\
\hline \multirow[t]{2}{*}{ Perceived severity: General } & How severe of a disease do you consider COVID-19 to be? ${ }^{\mathrm{b}}$ & 1,3 \\
\hline & COVID-19 is a very serious disease. ${ }^{c}$ & 2 \\
\hline Perceived severity: Likelihood to die & How likely do you think it is that a person who falls ill with COVID-19 dies as a result of the disease? ${ }^{\text {a }}$ & 3 \\
\hline Worry: Fall ill & How much do you worry about falling ill with COVID-19? & All \\
\hline Worry: Transmit & How much do you worry about transmitting COVID-19 to someone else? ${ }^{\mathrm{d}}$ & All \\
\hline \multicolumn{3}{|c|}{${ }^{2}$} \\
\hline Perceived likelihood of infection & If I do not take the influenza vaccine, I think my likelihood of falling ill with influenza during the next season (2020-2021) is ${ }^{\mathrm{a}}$ & 2,3 \\
\hline Perceived severity: Personal & How severe would it be for your health if you contracted influenza? ${ }^{\mathrm{b}}$ & 2,3 \\
\hline \multirow[t]{2}{*}{ Perceived severity: General } & Influenza is a very serious disease. ${ }^{\mathrm{c}}$ & 2 \\
\hline & How severe of a disease do you consider influenza to be? ${ }^{\mathrm{b}}$ & 3 \\
\hline Perceived severity: Likelihood to die & How likely do you think it is that a person who falls ill with influenza dies as a result of the disease? ${ }^{\text {a }}$ & 3 \\
\hline Worry: Fall ill & How much do you usually worry about falling ill with influenza? ${ }^{\mathrm{d}}$ & 2,3 \\
\hline Worry: Transmit & How much do you usually worry about transmitting influenza to someone else? ${ }^{\mathrm{d}}$ & 2,3 \\
\hline \multicolumn{3}{|c|}{ 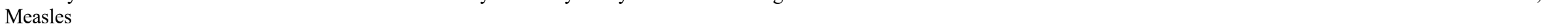 } \\
\hline Perceived likelihood of infection & If my child was unvaccinated against measles, I think the likelihood that my child falls ill with measles during the following 12 months is & 2,3 \\
\hline Perceived severity: Personal & How severe would it be for your child(ren)'s health to contract measles? & 2,3 \\
\hline \multirow[t]{2}{*}{ Perceived severity: General } & Measles is a very serious disease. ${ }^{\mathrm{c}}$ & 2 \\
\hline & How severe of a disease do you consider measles to be? ${ }^{\mathrm{b}}$ & 3 \\
\hline Perceived severity: Likelihood to die & How likely do you think it is that a person who falls ill with measles dies as a result of the disease? ${ }^{\mathrm{a}}$ & 3 \\
\hline Worry: Fall ill & How much do you usually worry about your child(ren) falling ill with measles?d & 2,3 \\
\hline Worry: Transmit & How much do you usually worry about your child(ren) transmitting measles to someone else? ${ }^{\mathrm{d}}$ & 2,3 \\
\hline
\end{tabular}

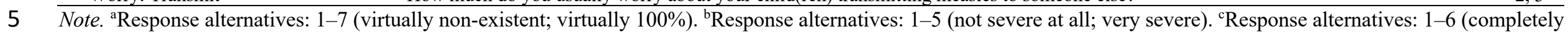

6 disagree; completely agree). ${ }^{\mathrm{d}}$ Response alternatives: 1-5 (not at all; very much). 
1

2

3

4

5

$6=$ hard to say, $4=$ quite likely, $5=$ very likely).

8

9

\subsubsection{Vaccination Intention}

\section{$7 \quad 3.3$ Statistical Analysis} 2020).

\section{STUDY 1 RESULTS}

To measure intentions to accept a vaccine against COVID-19, the respondents were asked "How likely do you consider it to be that you would take a vaccine against COVID-19, if such a vaccine was available, free of charge, and recommended to everyone by the authorities?". Response alternatives ranged from 1-5 $(1=$ very unlikely, $2=$ not that likely, 3

All analyses for Studies 1-3 were carried out in $R$, version 3.5.1 (R Core Team, 2018). In Study 1, we conducted a linear regression analysis with COVID-19 vaccination intentions as the outcome measure and the perceived disease-risk measures and age as predictors. Gender $(1=$ female; $2=$ male $)$ was included as a predictor because women have been found to perceive COVID-19 as a greater health risk than men (Galasso et al., 2020). On the other hand, the actual risk of COVID-19 has been found greater for men (Griffith et al.,

The parents' responses to the question on intentions to take a recommended vaccine against COVID-19 are presented in Table 2. Figure 1 and Supplementary Table S2 show the distribution of responses to the five measures on the perceived risk of COVID-19. Zero-order correlations between all measures can be found in Table 3 . 


\section{$1 \quad$ Table 2}

2 Responses to COVID-19 Vaccination-Intention Questions in the Three Current Studies

3

\begin{tabular}{lrrrrrr}
\hline \multirow{2}{*}{ Variable } & \multicolumn{2}{c}{ Study 1 } & \multicolumn{2}{c}{ Study 2 } & \multicolumn{2}{c}{ Study 3 } \\
\cline { 2 - 7 } & \multicolumn{1}{c}{$n$} & $\%$ & $n$ & $\%$ & $n$ & $\%$ \\
\hline Test-phase vaccine & - & - & 66 & 34.02 & 407 & 30.95 \\
1 Very unlikely & - & - & 37 & 19.07 & 227 & 17.26 \\
2 & - & - & 57 & 29.38 & 283 & 21.52 \\
3 & - & - & 25 & 12.89 & 249 & 18.94 \\
4 & - & - & 9 & 4.64 & 149 & 11.33 \\
5 Very likely & & & & & & \\
Recommended vaccine & 33 & 4.32 & 8 & 4.12 & 159 & 12.05 \\
1 Very unlikely & 57 & 7.31 & 15 & 7.73 & 55 & 4.17 \\
2 & 114 & 14.62 & 20 & 10.31 & 143 & 10.84 \\
3 & 202 & 25.90 & 49 & 25.26 & 288 & 21.83 \\
4 & 374 & 47.95 & 102 & 52.58 & 674 & 51.10 \\
5 Very likely & & & & & & \\
\end{tabular}

4 Note. In Study 1, labels for the options 2 (not that likely), 3 (hard to say), and 4 (quite likely) were provided.

5 Study 1: $45(5.5 \%)$ responses missing. Study 2: $11(5.4 \%)$ responses missing. Study 3: $10(0.8 \%)$ responses

6 missing concerning test-phase vaccine and $6(0.5 \%)$ responses missing concerning recommended vaccine. 


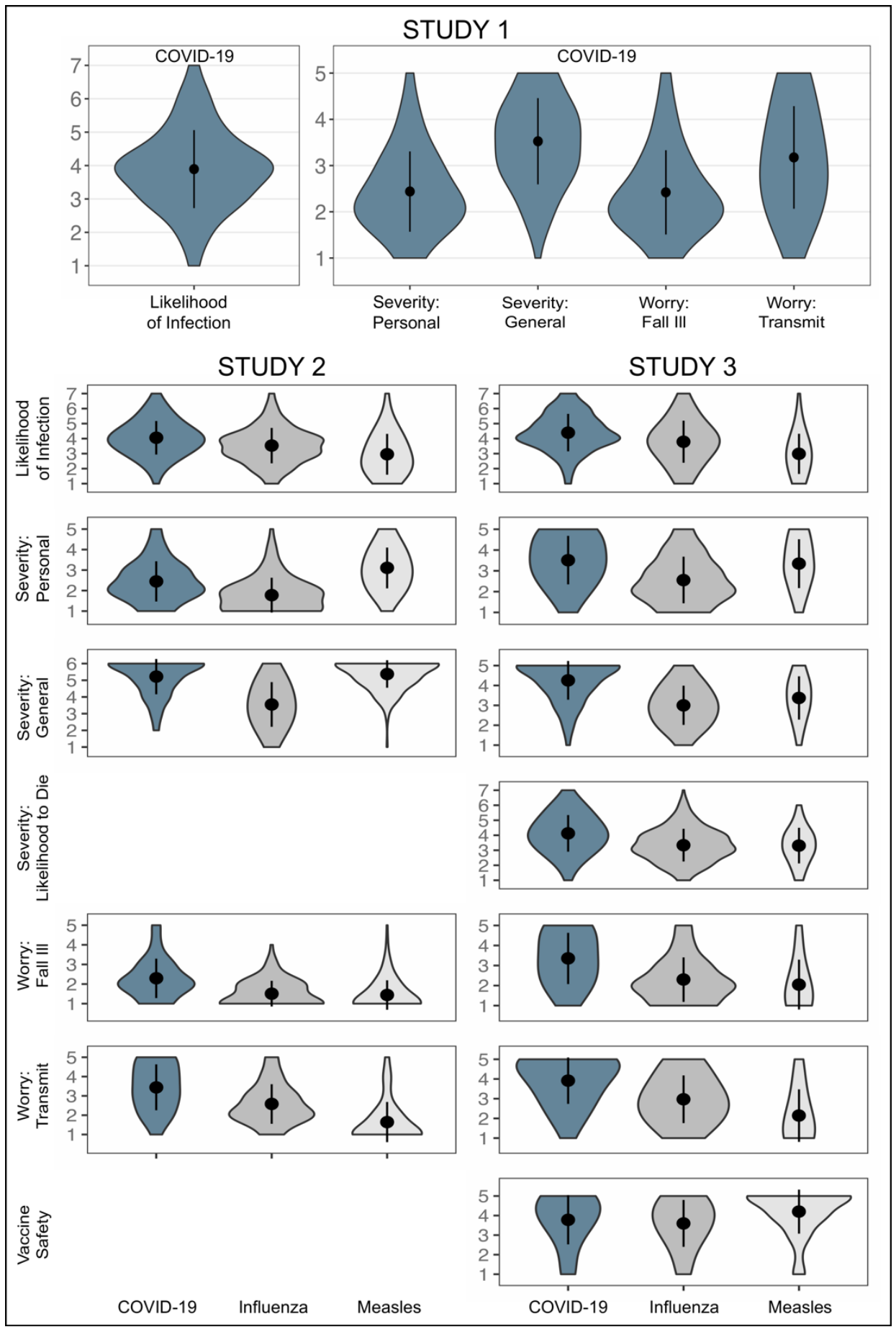

2 Figure 1. Perceived Disease Risk and Perceived Vaccine Safety.

3 Violin plots of the responses to the questions on perceived risk of COVID-19 and the

4 perceived safety of a recommended COVID-19 vaccine including dots for means and bars for

5 standard deviations. For Studies 2 and 3, violin plots for influenza and measles are also

6 presented. The outer borders of the violin shapes represent the frequency of responses. 


\section{Table 3}

2 Zero-Order Correlations Between all Measures in Study 1

\begin{tabular}{|c|c|c|c|c|c|c|c|}
\hline Variable & 1 & 2 & 3 & 4 & 5 & 6 & 7 \\
\hline 1. Perceived likelihood of infection & - & & & & & & \\
\hline 2. Perceived severity: Personal & .19 & - & & & & & \\
\hline 3. Perceived severity: General & .18 & .52 & - & & & & \\
\hline 4. Worry: Fall ill & .29 & .62 & .49 & - & & & \\
\hline 5. Worry: Transmit & .28 & .30 & .40 & .52 & - & & \\
\hline 6. Vaccination intentions: Recommended vaccine & .08 & .09 & .12 & .05 & .04 & - & \\
\hline 7. Age & -.02 & .13 & .02 & .01 & -.09 & .10 & - \\
\hline
\end{tabular}

3 Note. Pearson's $r$ correlations. Bolded correlations are statistically significant at $p<.05$. 
1 The results from the regression analysis $\left(F[7,771]=4.78, p<.001\right.$, adjusted $\left.R^{2}=.03\right)$

2 are shown in Table 4. Of the perceived risk measures, only perceived general severity of the

3 disease was statistically significantly associated with vaccination intentions $(\beta=.12, p=$

4 .009). Respondents perceiving COVID-19 as more severe in general were more likely to

5 accept the vaccine. Also, men were significantly more likely to intend to vaccinate against

6 COVID-19 than women $(\beta=.12, p<.001)$.

7

\section{$8 \quad$ Table 4}

9 Predictors of COVID-19 Vaccination Intentions in the Three Current Studies

\begin{tabular}{|c|c|c|c|c|c|c|}
\hline \multirow[b]{2}{*}{ Variable } & \multicolumn{2}{|c|}{ Standardized } & \multicolumn{2}{|c|}{ Unstandardized } & \multirow[b]{2}{*}{$t$} & \multirow[b]{2}{*}{$p$} \\
\hline & $\beta$ & $95 \% \mathrm{CI}$ & $b$ & $95 \% \mathrm{CI}$ & & \\
\hline \multicolumn{7}{|c|}{ Study 1} \\
\hline \multicolumn{7}{|l|}{ Recommended vaccine ${ }^{\mathrm{a}}$} \\
\hline Likelihood of infection & .07 & {$[-.00, .15]$} & 0.07 & {$[-0.00,0.14]$} & 1.95 & .052 \\
\hline Perceived severity: Personal & .04 & {$[-.05, .13]$} & 0.05 & {$[-0.07,0.18]$} & 0.86 & .392 \\
\hline Perceived severity: General & .12 & {$[.03, .20]$} & 0.14 & {$[0.04,0.25]$} & 2.62 & .009 \\
\hline Worry: Fall ill & -.05 & {$[-.15, .06]$} & -0.06 & {$[-0.18,0.07]$} & 0.88 & .379 \\
\hline Worry: Transmit & .02 & {$[-.06, .11]$} & 0.02 & {$[-0.06,0.11]$} & 0.51 & 607 \\
\hline Age & .07 & {$[-.00, .14]$} & 0.02 & {$[-0.00,0.03]$} & 1.90 & .057 \\
\hline Gender & .12 & {$[.05, .20]$} & 0.35 & {$[0.14,0.55]$} & 3.32 & $<.001$ \\
\hline \multicolumn{7}{|c|}{ Study 2} \\
\hline \multicolumn{7}{|l|}{ Test-phase vaccine ${ }^{\mathrm{b}}$} \\
\hline Perceived likelihood of infection & -.08 & {$[-.07, .24]$} & 0.09 & {$[-0.08,0.25]$} & 1.05 & 296 \\
\hline Perceived severity: Personal & -.15 & {$[-.33, .03]$} & -0.19 & {$[-0.41,0.04]$} & 1.66 & .099 \\
\hline Perceived severity: General & .23 & {$[.08, .38]$} & 0.26 & {$[0.09,0.44]$} & 2.94 & .004 \\
\hline Worry: Fall ill & .02 & {$[-.16, .21]$} & 0.03 & {$[-0.19,0.25]$} & 0.23 & .817 \\
\hline Worry: Transmit & .19 & {$[.02, .36]$} & 0.19 & {$[0.02,0.36]$} & 2.16 & .032 \\
\hline Age: $30-39$ vs. $18-29$ & -.15 & {$[-.31, .00]$} & -0.50 & {$[-0.99,0.00]$} & 1.97 & .050 \\
\hline Age: $40-49$ vs. $30-39$ & .02 & {$[-.16, .21]$} & 0.06 & {$[-0.39,0.51]$} & 0.25 & .800 \\
\hline Age: $50-59$ vs. $40-49$ & .18 & {$[-.03, .39]$} & 0.46 & {$[-0.09,1.02]$} & 1.65 & .101 \\
\hline Age: $60+$ vs. $50-59$ & .02 & {$[-.16, .20]$} & 0.06 & {$[-0.54,0.66]$} & 0.20 & .839 \\
\hline Gender & .26 & {$[.12, .41]$} & 0.69 & {$[0.31,1.06]$} & 3.64 & $<.001$ \\
\hline \multicolumn{7}{|l|}{ Recommended vaccine ${ }^{\mathrm{b}}$} \\
\hline Perceived likelihood of infection & .09 & {$[-.06, .24]$} & 0.09 & {$[-0.06,0.25]$} & 1.19 & .237 \\
\hline Perceived severity: Personal & -.05 & {$[-.23, .12]$} & -0.06 & {$[-0.27,0.14]$} & 0.59 & .554 \\
\hline Perceived severity: General & .24 & {$[.09, .39]$} & 0.26 & {$[0.10,0.42]$} & 3.19 & .002 \\
\hline Worry: Fall ill & .03 & {$[-.15, .21]$} & 0.04 & {$[-0.17,0.24]$} & 0.37 & .711 \\
\hline Worry: Transmit & .26 & {$[.09, .42]$} & 0.25 & {$[0.09,0.41]$} & 3.06 & .003 \\
\hline Age: $30-39$ vs. $18-29$ & -.06 & {$[-.21, .09]$} & -0.19 & {$[-0.65,0.27]$} & 0.83 & .408 \\
\hline Age: $40-49$ vs. $30-39$ & .24 & {$[.05, .42]$} & 0.54 & {$[0.12,0.96]$} & 2.55 & .012 \\
\hline Age: $50-59$ vs. $40-49$ & -.13 & {$[-.34, .07]$} & -0.33 & {$[-0.85,0.18]$} & 1.27 & .206 \\
\hline Age: $60+$ vs. $50-59$ & .04 & {$[-.13, .22]$} & 0.14 & {$[-0.41,0.70]$} & 0.50 & .616 \\
\hline Gender & .23 & {$[.09, .37]$} & 0.57 & {$[0.23,0.92]$} & 3.28 & .001 \\
\hline \multicolumn{7}{|c|}{ Study 3} \\
\hline Test-phase vaccine ${ }^{c}$ & & & & & & \\
\hline Perceived likelihood of infection & .07 & {$[.01, .13]$} & 0.08 & {$[0.01,0.14]$} & 2.29 & .022 \\
\hline Perceived severity: Personal & .03 & {$[-.06, .11]$} & 0.03 & {$[-0.07,0.14]$} & 0.62 & .534 \\
\hline
\end{tabular}




\begin{tabular}{|c|c|c|c|c|c|c|}
\hline Perceived severity: General & -.04 & {$[-.12, .05]$} & -0.06 & {$[-0.18,0.06]$} & 0.91 & .361 \\
\hline Perceived severity: Likelihood to die & .09 & {$[.02, .16]$} & 0.10 & {$[0.02,0.19]$} & 2.42 & .016 \\
\hline Worry: Fall ill & -.03 & {$[-.12, .05]$} & -0.04 & {$[-0.13,0.06]$} & 0.77 & .442 \\
\hline Worry: Transmit & .00 & {$[-.08, .07]$} & 0.00 & {$[-0.09,0.09]$} & 0.02 & .985 \\
\hline Perceived vaccine safety & .51 & {$[.46, .57]$} & 0.56 & {$[0.50,0.63]$} & 17.22 & $<.001$ \\
\hline Prevalence & .04 & {$[-.01, .09]$} & 0.12 & {$[-0.04,0.27]$} & 1.51 & .132 \\
\hline Age & .14 & {$[.09, .20]$} & 0.02 & {$[0.01,0.02]$} & 4.89 & $<.001$ \\
\hline Gender & .08 & {$[.02, .13]$} & 0.27 & {$[0.08,0.47]$} & 2.80 & .005 \\
\hline \multicolumn{7}{|l|}{ Recommended vaccine $^{\mathrm{d}}$} \\
\hline Perceived likelihood of infection & .05 & {$[.01, .90]$} & 0.06 & {$[0.01,0.10]$} & 2.42 & .016 \\
\hline Perceived severity: Personal & .06 & {$[-.01, .12]$} & 0.07 & {$[-0.01,0.14]$} & 1.79 & .073 \\
\hline Perceived severity: General & .07 & {$[.01, .13]$} & 0.10 & {$[0.02,0.19]$} & 2.42 & .016 \\
\hline Perceived severity: Likelihood to die & .00 & {$[-.05, .05]$} & 0.00 & {$[-0.06,0.06]$} & 0.01 & .990 \\
\hline Worry: Fall ill & .03 & {$[-.03, .09]$} & 0.03 & {$[-0.04,0.10]$} & 0.90 & .371 \\
\hline Worry: Transmit & -.00 & {$[-.06, .05]$} & -0.01 & {$[-0.07,0.06]$} & 0.17 & .863 \\
\hline Perceived vaccine safety & .72 & {$[.68, .76]$} & 0.78 & {$[0.73,0.82]$} & 33.67 & $<.001$ \\
\hline Prevalence & .00 & {$[-.03, .04]$} & 0.01 & {$[-0.10,0.12]$} & 0.15 & .878 \\
\hline Age & .04 & {$[.00, .09]$} & 0.00 & {$[0.00,0.01]$} & 2.13 & .034 \\
\hline Gender & .04 & {$[-.00, .08]$} & 0.13 & {$[-0.01,0.26]$} & 1.82 & .069 \\
\hline
\end{tabular}

Note. List-wise deletion of missing values. Statistically significant results are bolded. Gender coded as $1=$

2 female and $2=$ male. ${ }^{\mathrm{a}} n=779 .{ }^{\mathrm{b}} n=188 .{ }^{\mathrm{c}} n=973 .{ }^{\mathrm{d}} n=977$.

3

\section{STUDY 1 DISCUSSION}

Most parents did not expect COVID-19 to pose a great risk for their personal health although they considered the disease as severe and many worried about transmitting it to others. The majority of parents $(73.9 \%)$ considered the likelihood that they would accept a vaccine against COVID-19 as high (response alternatives 4 and 5 on the 5-point scale), if such a vaccine were available and recommended by authorities. Interestingly, the only aspect of perceived disease risk that played a role in the respondents' vaccination intentions was perceptions of the general severity of COVID-19, so that those who perceived COVID-19 as a more severe disease were more likely to intend to vaccinate. Also, men had higher vaccination intentions than women. Both associations were, however, small. The model explained only $3 \%$ of the variance in vaccination intentions. None of the variables concerning the respondents' personal health predicted intentions to vaccinate. It is worth noting that the age distribution of the sample was narrow, and the respondents were relatively young, with 96.4\% being between 30 and 49 years old (Supplementary Table S1). Study 1, therefore, suggested that the motivating factor to get vaccinated against COVID-19 is not related to 
1 how severe people perceive the disease to be for their own health, but rather to how serious

2 they think the disease is for people in general — at least in this relatively young sample.

Study 2 used a sample with a broader age range. In Study 2, people's perceptions of

4 COVID-19 were compared to those concerning influenza and measles. Vaccine safety was

5 also included by examining how willing individuals were to accept a test-phase COVID-19

6 vaccine - a vaccine likely considered less safe because of the ongoing tests.

7 6 STUDY 2 METHOD

\section{$8 \quad 6.1$ Respondents and Procedure}

In April 2019, 5,000 18-65-year-old individuals living in the Pietarsaari region in Finland were invited to an online survey on vaccine attitudes. The region was originally targeted because of the lower uptake of several vaccines included in the national vaccination program compared to other Finnish regions. A total of 1,139 (22.8\%) invitees responded to the survey and 335 (29.4\%) consented to being contacted again and provided a valid e-mail address. On March $30^{\text {th }}, 2020$, these 335 respondents were invited to an online survey on the coronavirus pandemic. The survey was open for two weeks and 205 (61.2\%) individuals replied. No compensation for participation was provided. In Study 2, 110 (29.4\%) respondents were between 50-65 years old (compared to Study 1, where 99\% of the respondents were younger than 50 years; see Supplementary Table S1 for sample descriptives), and 137 (66.8\%) reported having children. Ethical approval was received from the Board for Research Ethics at Åbo Akademi University. Informed consent to participate was given electronically.

\subsection{Measures}

\subsubsection{Perceived Disease Risk}

Perceived likelihood of infection with, perceived severity of, and worry about COVID-19 were measured with the same questions and response alternatives as in Study 1, 
1 with the exception that the measure of perceived general severity was formulated as a

2 statement instead of a question. The respondents indicated whether they agreed with the

3 statement on a 6-point scale with the anchors 1 (completely disagree) and 6 (completely

4 agree). Additionally, corresponding questions related to influenza and measles were

5 administered (Table 1). The measures of the perceived risk of COVID-19 were not

6 administered if the respondent reported having tested positive for the disease. The questions

7 related to measles were only administered to respondents who reported having children,

8 except for the question on the general severity of measles that was presented to all

9 respondents.

\subsubsection{Vaccination Intention}

The question on intentions to accept a recommended COVID-19 vaccine differed

slightly from that in Study 1 and read: "Imagine a hypothetical scenario where the authorities recommend a new vaccine against COVID-19 free of charge. How likely do you consider it to be that you would accept such a vaccine?". Willingness to take a test-phase vaccine against COVID-19 was measured with the question: "Imagine a hypothetical scenario where you would be offered the possibility to participate in a trial of a new vaccine against COVID-19 that is under development. How likely do you consider it to be that you would accept such a vaccine?’. Respondents answered on a 5-point scale with the anchors 1 (very unlikely) and 5 19 (very likely).

\subsection{Statistical Analyses}

We tested the difference between the respondents' willingness to take a recommended

22 COVID-19 vaccine and a test-phase vaccine using paired $t$-tests. Then, whether the perceived

23 disease-risk measures, age, and gender $(1=$ female; $2=$ male $)$ predicted intentions to take a recommended COVID-19 vaccine and a test-phase vaccine was investigated in two linear regression analyses. In Study 2, the age measure was categorical, as the respondents reported 
1 which of the following age spans they belonged to: 18-29, 30-39, 40-49, or 50-59 years old,

2 or $60+$ years old. The variable was dummy coded so that each age span was compared to the

3 preceding age span.

$4 \quad$ Additional analyses can be found in the online supplementary material. In these

5 analyses, we statistically tested the differences in risk perceptions between the diseases

6 (Table S4 and S5). Furthermore, we investigated whether intentions to take the influenza

7 vaccine for oneself, and intentions to accept childhood vaccines for one's children (Table S3)

8 were predicted by their respective perceived risk measures, respondent age, and gender

9 (Table S6).

107 STUDY 2 RESULTS

11 Table 2 shows the responses to the questions on COVID-19 vaccination intentions.

12 The distributions of responses to the questions on perceived disease risk are shown in

13 Figure 1 and in Supplementary Table S2. Zero-order correlations between all measures

14 related to COVID-19 are shown in Table 5. 


\section{Table 5}

2 Zero-Order Correlations Between Measures Related to COVID-19 in Study 2

\begin{tabular}{|c|c|c|c|c|c|c|c|c|}
\hline Variable & 1 & 2 & 3 & 4 & 5 & 6 & 7 & 8 \\
\hline 1. Perceived likelihood of infection & - & & & & & & & \\
\hline 2. Perceived severity: Personal & .22 & - & & & & & & \\
\hline 3. Perceived severity: General & .10 & .42 & - & & & & & \\
\hline 4. Worry: Fall ill & .30 & .57 & .34 & - & & & & \\
\hline 5. Worry: Transmit & .44 & .30 & .21 & .50 & - & & & \\
\hline 6. Vaccination intentions: Recommended vaccine & .17 & .13 & .27 & .18 & .29 & - & & \\
\hline 7. Vaccination intentions: Test-phase vaccine & .09 & .05 & .18 & .07 & .19 & .50 & - & \\
\hline 8. Age & -.08 & .28 & .25 & .04 & -.04 & .15 & .15 & - \\
\hline
\end{tabular}

$3 \quad$ Note. Pearson's $r$ correlations. Bolded correlations are statistically significant at $p<.05$. 
Respondents reported a significantly higher intention to take a recommended vaccine against COVID-19 than a test-phase vaccine $(t[193]=21.40, p<.001)$. The difference between the two types of vaccines was large $(d=1.53)$.

The results from the two linear regression analyses with intentions to take a test-phase vaccine $\left(F[10,177]=4.17, p<.001\right.$, adjusted $\left.R^{2}=.14\right)$ and a recommended vaccine $(F[10$, $177]=5.31, p<.001$, adjusted $\left.R^{2}=.19\right)$ against COVID-19 as outcomes are presented in Table 4. Respondents who perceived COVID-19 as a more severe disease $(\beta=.23, p=.004)$, who worried more about transmitting COVID-19 $(\beta=.19, p=.032)$, and who were male $(\beta=$ $.26, p<.001)$ were more likely to accept a test-phase COVID-19 vaccine. The same variables also significantly predicted willingness to accept a COVID-19 vaccine recommended by authorities, as those perceiving COVID-19 as more severe $(\beta=.24, p=.002)$, who worried more about transmitting the disease $(\beta=.26, p=.003)$, and male respondents $(\beta=.23, p=$ .001) had higher intentions to accept a recommended vaccine. In addition, individuals in their 40 s reported significantly higher intentions to accept the vaccine than those in their $30 \mathrm{~s}(\beta=$ $.24, p=.012)$.

\section{STUDY 2 DISCUSSION}

Respondents did not consider COVID-19 to constitute a high risk to their personal health, but the great majority $(77.8 \%)$ considered the likelihood that they would take a recommended COVID-19 vaccine as high. Only $\sim 18 \%$ reported a high likelihood for accepting a test-phase vaccine if offered. Considering the high acceptance of a recommended vaccine among the respondents, as well as their willingness to be contacted for research purposes and the high response rate, this sample might not be representative of the general population in the Pietarsaari region.

As in Study 1, the perceived risk of COVID-19 to the respondent's own health did not predict vaccination intentions. Instead, those who believed that COVID-19 was a severe 
disease, worried about transmitting it to others, and were male, were more likely to accept a test-phase and a recommended vaccine against COVID-19. The variables accounted for $14 \%$ of the variance in willingness to take a test-phase vaccine, and $19 \%$ of the variance in willingness to take a vaccine recommended by authorities.

In summary, the results from Study 2 are in line with the conclusions from Study 1, suggesting that a more important factor in predicting whether people will accept a COVID-19 vaccine is how threatening they consider the disease to be to others than how threatening they consider it to be for themselves. This finding was even clearer in Study 2, where both variables that measured perceived risk of COVID-19 to others, played a role in the intentions to vaccinate. However, also these respondents were relatively young with the majority being below 50 years of age. The low willingness to accept a test-phase vaccine indicates that when vaccine safety is less certain, vaccination rates might drop dramatically even though the disease is considered severe.

Study 3 further examined the role of perceived vaccine safety by including a question probing how much the respondents trust that a recommended vaccine against COVID-19 would be safe. Study 3 also included an additional measure of perceived severity (the perceived likelihood of death from the disease) and an objective measure of disease risk (residing in Uusimaa vs. other Finnish region).

\section{STUDY 3 METHOD}

\subsection{Respondents and Procedure}

Respondents were recruited via a marketed Facebook post with a link to an online survey. The post was marketed for two weeks, between the $3^{\text {rd }}$ and $17^{\text {th }}$ of April 2020, and reached 97,408 Facebook users. The survey was viewed by 3,305 (3.4\%) individuals, of whom 2,233 (67.6\%) started to fill out the questionnaire. The 1,325 individuals who reached the end of the questionnaire (i.e., had responded to questions on the last page of the survey) 
and answered correctly to an attention check question were included. Their mean age was $47.71(S D=13.11$, range $=18-100 ;$ see, Supplementary Table S1 for sample descriptives $)$. The Board for Research Ethics at Åbo Akademi University approved the study. Respondents gave their informed consent to participate in the study electronically. They did not receive any compensation for their participation.

\subsection{Measures}

\subsubsection{Perceived Disease Risk}

The questions and response alternatives related to perceived likelihood of infection with, perceived severity of, and worry about COVID-19 administered in Study 1 were administered in Study 3 as well (Table 1). The corresponding measures related to influenza and measles were the same as in Study 2, with the exception that the questions on perceived general severity of influenza and measles were reformulated to correspond to the COVID-19

question from Study 1. Furthermore, an additional measure of perceived severity for each disease was included, querying the likelihood of death from COVID-19/influenza/measles. Respondents gave their response on a scale from $1-7(1=$ virtually non-existent, $2=$ very small, $3=$ small, $4=$ medium sized, $5=$ large, $6=$ very large, $7=$ virtually $100 \%$ ). The questions on COVID-19 were not administered if the respondent reported having tested positive for the disease. The questions on measles were only administered to respondents with children younger than 18 .

\subsubsection{Perceived Vaccine Safety}

To measure perceptions of vaccine safety, respondents were presented with the statements "If a vaccine against COVID-19 became part of the recommended vaccines in Finland, I would trust that it is safe", "The influenza vaccines are safe", and "The measles vaccine is safe". They indicated whether they agree on a 5-point scale with the anchors 1 (completely disagree) and 5 (completely agree). 


\subsubsection{Disease Prevalence}

During the time of the data collection, the Uusimaa region had a higher prevalence of COVID-19 than any other Finnish region. Movement to and from Uusimaa was restricted by the government (Finnish Government, 2020b). The respondents were asked to indicate their region of residence. A variable coded as 1 if they reported living in Uusimaa, or 0 if they did not live in Uusimaa, was created.

\subsubsection{Vaccination Intention}

The questions on intentions to accept a recommended vaccine and a test-phase vaccine against COVID-19 were the same as in Study 2.

\subsection{Statistical Analysis}

As in Study 2, we compared the respondents' intentions to take a recommended and a test-phase COVID-19 vaccine using paired $t$-tests. Two linear regression analyses were then conducted - one with the recommended COVID-19 vaccine as the outcome, and another with the test-phase COVID-19 vaccine as the outcome. The outcomes were regressed on the measures of perceived risk, perceived vaccine safety, disease prevalence, age, and gender (1 $=$ female; $2=$ male). The additional analyses conducted in Study 2 were conducted in Study 3 as well (see, online supplemental material).

\section{STUDY 3 RESULTS}

Responses to the questions on COVID-19 vaccination intentions are shown in Table 2. The distribution of the responses to the questions on perceived risk and perceived vaccine safety are shown in Figure 1 and Supplementary Table S2. Zero-order correlations between all measures related to COVID-19 are presented in Table 7. 


\section{Table 7}

Zero-Order Correlations Between Measures Related to COVID-19 in Study 3

\begin{tabular}{|c|c|c|c|c|c|c|c|c|c|c|}
\hline Variable & 1 & 2 & 3 & 4 & 5 & 6 & 7 & 8 & 9 & 10 \\
\hline 1. Perceived likelihood of infection & - & & & & & & & & & \\
\hline 2. Perceived severity: Personal & .41 & - & & & & & & & & \\
\hline 3. Perceived severity: General & .37 & .68 & - & & & & & & & \\
\hline 4. Perceived severity: Likelihood die & .37 & .63 & .67 & - & & & & & & \\
\hline 5. Worry: Fall ill & .46 & .77 & .65 & .60 & - & & & & & \\
\hline 6. Worry: Transmit & .46 & .51 & .59 & .50 & .63 & - & & & & \\
\hline 7. Vaccine safety & .22 & .34 & .48 & .33 & .36 & .37 & - & & & \\
\hline 8. Vaccination intentions: Recommended vaccine & .27 & .40 & .50 & .35 & .41 & .39 & .81 & - & & \\
\hline 9. Vaccination intentions: Test-phase vaccine & .16 & .25 & .29 & .25 & .23 & .22 & .58 & .61 & - & \\
\hline 10. Age & -.12 & .23 & .23 & .16 & .10 & -.06 & .21 & .21 & .25 & - \\
\hline
\end{tabular}

Note. Pearson's $r$ correlations. Bolded correlations are statistically significant at $p<.05$. 
The difference between the respondents' willingness to take a recommended vaccine and a test-phase vaccine against COVID-19 was statistically significant and large $(t[1314]=$ 40.20, $p<.001, d=1.11)$.

Table 4 shows the results from the two regression analyses on predictors of willingness to take a test-phase $\left(F[10,962]=55.04, p<.001\right.$, adjusted $\left.R^{2}=.36\right)$ and a recommended vaccine against COVID-19 $\left(F[10,966]=201.60, p<.001\right.$, adjusted $\left.R^{2}=.67\right)$. Respondents who perceived the likelihood of contracting COVID-19 as higher $(\beta=.07, p=$ $.022)$, the likelihood of death from COVID-19 as higher $(\beta=.09, p=.016)$, those who trusted the safety of a prospective vaccine more $(\beta=.51, p<.001)$, and men $(\beta=.08, p=.005)$ reported significantly more willingness to accept a test-phase vaccine. In addition, higher age was related to a higher willingness to take a test-phase vaccine $(\beta=.14, p<.001)$.

Concerning the recommended COVID-19 vaccine, respondents who perceived the likelihood of contracting the disease as higher $(\beta=.05, p=.016)$, who considered COVID-19 a more severe disease $(\beta=.07, p=.016)$, who had higher trust in the vaccine being safe $(\beta=.72, p<$ $.001)$, and who were older $(\beta=.04, p=.034)$ were significantly more likely to accept vaccination.

\section{STUDY 3 DISCUSSION}

The majority of the respondents (72.9\%) considered the likelihood that they would accept a vaccine against COVID-19 as high, if such a vaccine was offered and recommended by authorities. When it comes to a test-phase vaccine, $\sim 30 \%$ considered the likelihood high that they would agree to the vaccine. Vaccine safety showed the strongest relationship with vaccination intentions, explaining $52 \%$ of unique variance in intentions to accept a recommended COVID-19 vaccine. The measures of perceived risk of COVID-19 were weakly related to vaccination intentions. As in Studies 1 and 2, the perceived severity measures that reached statistical significance probed the perceived risk of COVID-19 to 
people in general, and not specifically to oneself. Those perceiving COVID-19 as a severe disease were slightly more likely to intend to take a recommended vaccine, whereas those perceiving the likelihood of death from COVID-19 as higher were slightly more willing to accept a test-phase vaccine. Contrary to the results of Studies 1 and 2, the respondents' perceived risk to contract COVID-19 also predicted vaccination intentions. However, the perceived risk measures accounted for only $0.2-0.8 \%$ of the variance in vaccination intentions. The objective risk of contracting COVID-19 was not associated with people's willingness to vaccinate, as there was no difference in vaccination intentions between those living in Uusimaa and those living in regions with lower COVID-19 prevalence.

Furthermore, the older the respondents were, the more likely they were to intend to take the two types of vaccines. The fact that age predicted vaccination intentions in Study 3, but not in Studies 1 and 2, might stem from the fact that Study 3 included a sample with the broadest age range. Also, the power in Study 3 was higher, allowing us to detect smaller effects. Finally, men were slightly more likely to accept a test-phase vaccine than women, whereas there were no significant gender differences in intention to take a recommended COVID-19 vaccine.

\section{GENERAL DISCUSSION}

The aims of the present study were 1) to examine people's perceptions of the risk of COVID-19 and the safety of a prospective vaccine against COVID-19, and 2) to investigate if the perceived disease risk and perceived vaccine safety are related to intentions to take a COVID-19 vaccine. As a point of reference, we also measured perceptions of influenza and measles.

Across the current three studies, individuals commonly considered COVID-19 to be a very severe disease, although they expected to experience less severe symptoms themselves. Individuals also worried more about transmitting the disease to others than about falling ill 
personally. Previous research has found an optimistic bias in risk ratings of COVID-19, as individuals commonly consider their own risks as smaller compared to others (Park et al., 2020; Wise et al., 2020).

Approximately $3 / 4$ of the individuals considered the likelihood that they would accept a recommended vaccine against COVID-19 to be high (i.e., chose the response alternatives 4 or 5 on the 5 -point scale; $73.9 \%$ in the sample of parents, $77.8 \%$ in the sample in the Pietarsaari region, and $72.9 \%$ in the nationwide sample of Facebook users). Other studies have found acceptance rates of $67 \%$ in the US (Malik et al., 2020), 81-86\% in Australia (Dodd et al., 2020; Faasse \& Newby, 2020), and between $62-85 \%$ in other European countries (Blanchard-Rohner et al., 2020 [pre-print]; Murphy et al., 2020 [pre-print]; Neumann-Böhme et al., 2020). For the test-phase vaccine, the acceptance rates were $17.5 \%$ and $30.3 \%$ in the present study.

\subsection{Predictors of Vaccination Intentions}

Importantly, the strongest predictor of intentions to accept a COVID-19 vaccine recommended by authorities was the degree to which respondents trusted the vaccine to be safe. Perceived vaccine safety explained $52 \%$ of the variance in intentions to vaccinate. Across the three studies, how serious the respondents thought COVID-19 was for people in general also predicted higher vaccination intentions, but the predictive value was much smaller (explaining $0.5-5.8 \%$ of the variance in intention to accept a recommended COVID19 vaccine). Taken together, this means that individuals who perceive the disease as severe might still choose not to vaccinate if they consider the vaccine unsafe. However, individuals who perceive the vaccine as safe might be willing to take the vaccine although they would not consider the disease as severe (Figure 2 visualizes this relationship). In the present study, $15.4 \%$ of respondents reported that they did not trust a vaccine against COVID-19 recommended by authorities to be safe, and another $15.4 \%$ were unsure. The fact that the 
acceptance rates of a test-phase vaccine, which might be considered less safe, were considerably lower than those of the recommended vaccines also suggests that vaccine safety plays a major role in willingness to take a COVID-19 vaccine. A recent study of seven European countries found that the majority of individuals who were unsure about whether they would accept a COVID-19 vaccine or not, and those who would reject the vaccine, expressed fear of side effects as the reason for their hesitancy (Neumann-Böhme et al., 2020). Concerns about vaccine safety can, thus, be expected to constitute the largest future challenge for health authorities when trying to achieve a high uptake of a COVID-19 vaccine.

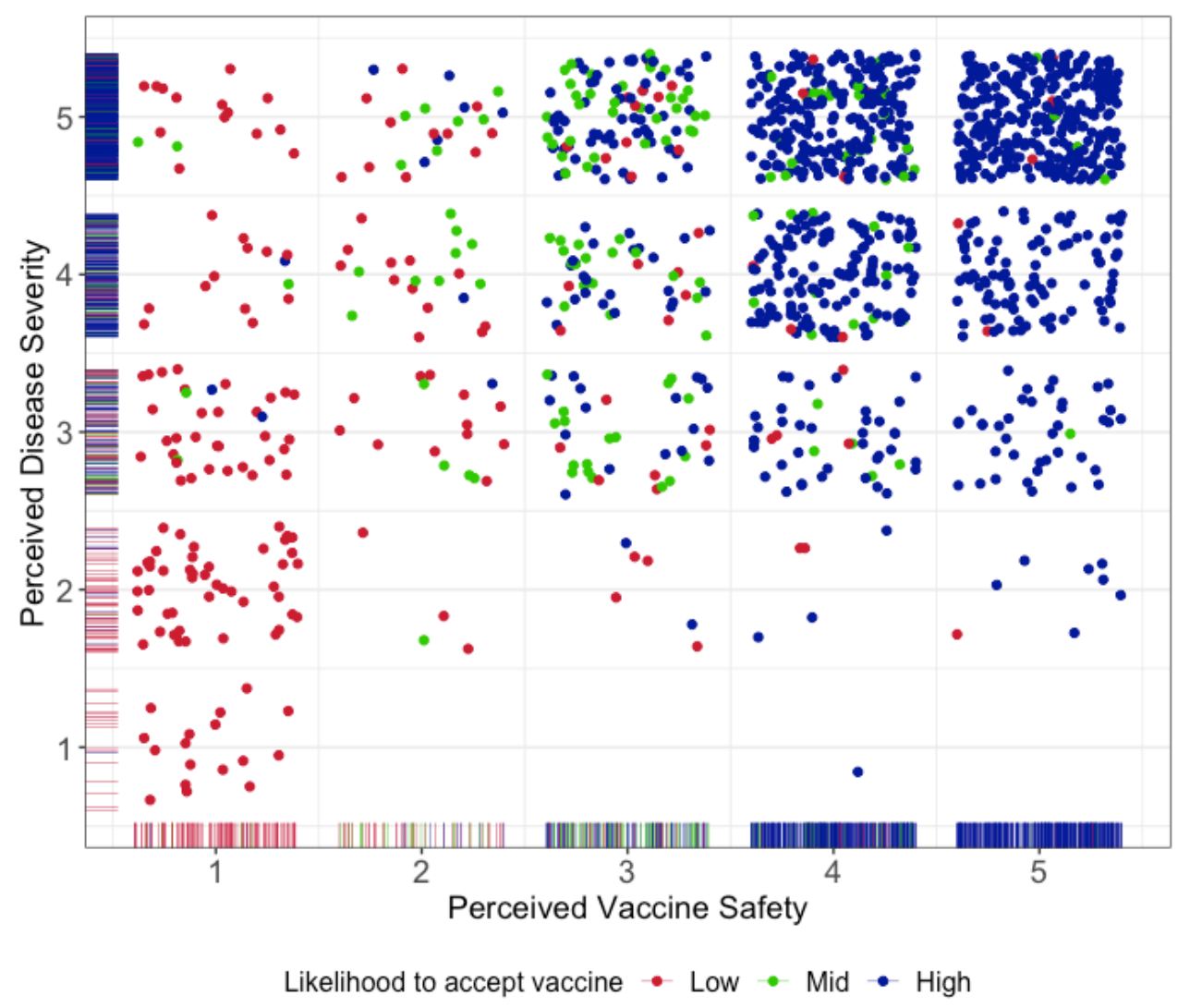

Figure 2. COVID-19 Vaccination Intentions

Perceived general severity of COVID-19 (y-axis) plotted by perceived safety of a prospective COVID-19 vaccine (x-axis) in Study 3. The degree to which the respondents report being likely to accept a vaccine against COVID-19 recommended by authorities is represented by 
blue (response alternative 4 or 5 on the scale ranging from 1 [very unlikely] to 5 [very likely]), green (response alternative 3), and red (response alternative 1 or 2) dots. Marginal distributions are represented by rugs.

Contrary to expectations, the perceived risk of COVID-19 to one's personal health was not robustly associated with intentions to vaccinate. This contrasts with previous research that has found higher perceived likelihood of infection (Glöckner et al., 2020 [preprint]) and more worry about contracting COVID-19 (Ward et al., 2020) to predict higher vaccination intentions. However, Faasse and Newby (2020) also found the risk of COVID-19 to one's personal health to be only weakly related to vaccination intentions. The fact age did not show any considerable (linear) association with vaccine acceptance further supports the notion that personal disease risk plays a minor role in the vaccination decision. Even when someone does not expect to experience severe symptoms of COVID-19 themselves, they might still be motivated to vaccinate to protect others from a potentially severe disease.

The practical implication of the above-mentioned results is that, to ensure sufficient uptake of an approved COVID-19 vaccine, communications that underscore the safety of the vaccine are more important than highlighting the risks of the disease. It is, however, worth noting that perceived vaccine safety was moderately correlated with how severe the respondents perceived COVID-19 to be for people in general. Those who perceived the disease as mild, often also perceived the vaccine as unsafe (Figure 2). If this is because people evaluate the safety of the vaccine in relation to how severe they perceive the disease to be, then it is possible that communication emphasizing the risks of the disease influence vaccine perceptions. However, it is also possible that the relationship between perceived vaccine safety and perceived severity of COVID-19 could be explained by a third variable, such as general lack of trust in information provided by medical authorities. 
As respondent age and prevalence of COVID-19 did not show any notable relationship with intentions to accept a recommended COVID-19 vaccine, the present study also suggests that communication on vaccine safety should be directed towards individuals at all ages and geographical areas. Women were less willing to accept COVID-19 vaccination than men, but the size of the gender difference varied between studies, and most of the differences were small. Specifically targeting women in communication on a COVID-19 vaccine might, therefore, not be essential.

\subsection{Limitations}

The present study had some limitations. First, the cross-sectional design did not allow for robust conclusions concerning causality. Second, the fact that the data collections took place during the first peak of the pandemic can be considered both a strength and a limitation. On the one hand, it provided information on individuals' perceptions of COVID-19 during acute circumstances. However, vaccinations against COVID-19 might be introduced at a stage of the pandemic when individuals have been habituated to the threat. Research conducted during the swine flu pandemic indicated that the perceived risk of the swine flu decreased as the pandemic progressed (Bults, Beaujean, Richardus, \& Voeten, 2015). Glöckner et al. (2020 [pre-print]) conducted three cross-sectional studies in Germany during the growth stage of the COVID-19 pandemic and when the growth curve flattened. They found that perceived risk of COVID-19 decreased after the pandemic peak. Acceptance rates and associations need to be repeatedly studied as the pandemic develops.

Third, the measures administered were developed by the authors and had not been independently validated. However, the formulation of the questions related to the perceived likelihood and severity of disease followed recommendations on the development of reliable risk-perception measures (Brewer et al., 2007). The remaining measures corresponded to 
those commonly used in research on the subject. We therefore place confidence in our measures.

Fourth, we did not measure the exact age of respondents in Study 2. The respondents were instead asked to indicate which ten-year age span they belonged to. To account for this, age was dummy coded for the analyses.

Lastly, there were minor discrepancies between the studies in some of the measures. There were two reasons for these discrepancies: 1) the samples in Studies 1 and 2 were part of longitudinal studies and we formulated the questions to enable comparison between the two time points, and 2) in Study 1, the vaccination intention measure was adapted to correspond to the structure of a larger COVID-19 survey.

\subsection{Conclusions}

Across three Finnish samples, individuals perceived COVID-19 as a severe disease and worried about transmitting it to others. Respondents were, however, less concerned about the risk of the disease to their own health, especially in the younger samples. Approximately $3 / 4$ of respondents reported they would take a vaccine against COVID-19, if such a vaccine was available and recommended by authorities. The strongest predictor of having high intentions to take a COVID-19 vaccine was trusting the vaccine to be safe. Higher vaccination intentions were also somewhat more likely for respondents perceiving the disease as more severe, than for those considering COVID-19 as a mild disease.

Informing the public about the safety of a forthcoming vaccine is of paramount importance to health authorities planning to roll out large-scale vaccinations in the near future. Highlighting the fact that COVID-19 can have detrimental health consequences for those infected, may also positively affect vaccine uptake although the magnitude of that effect may be smaller.

\section{REFERENCES}


Betsch, C., Schmid, P., Heinemeier, D., Korn, L., Holtmann, C., \& Böhm, R. (2018). Beyond confidence: Development of a measure assessing the 5C psychological antecedents of vaccination. PLoS ONE, 13(12), 1-32. https://doi.org/10.1371/journal.pone.0208601

Bish, A., Yardley, L., Nicoll, A., \& Michie, S. (2011). Factors associated with uptake of vaccination against pandemic influenza: A systematic review. Vaccine, 29(38), 64726484. https://doi.org/10.1016/j.vaccine.2011.06.107

Blanchard-Rohner, G., Caprettini, B., Rohner, D., \& Voth, H. (2020). Impact of COVID-19 and health system performance on vaccination hesitancy: Evidence from a two-leg representative survey in the UK. SSRN Electronic Journal, 1-40. https://doi.org/10.2139/ssrn.3627335

Brewer, N. T., Chapman, G. B., Gibbons, F. X., Gerrard, M., McCaul, K. D., \& Weinstein, N. D. (2007). Meta-analysis of the relationship between risk perception and health behavior: The example of vaccination. Health Psychology, 26(2), 136-145. https://doi.org/10.1037/0278-6133.26.2.136

Brewer, N. T., Chapman, G. B., Rothman, A. J., Leask, J., \& Kempe, A. (2017). Increasing vaccination: Putting psychological science into action. Psychological Science in the Public Interest, 18(3), 149-207. https://doi.org/10.1177/1529100618760521

Bults, M., Beaujean, D. J. M. A., Richardus, J. H., \& Voeten, H. A. C. M. (2015). Perceptions and behavioral responses of the general public during the 2009 influenza A (H1N1) pandemic: A systematic review. Disaster Medicine and Public Health Preparedness, 9(2), 207-219. https://doi.org/10.1017/dmp.2014.160

Callaway, E. (2020). The race for coronavirus vaccines: a graphical guide. Nature, 580, 576577. https://doi.org/10.1038/d41586-020-01221-y

Centers for Disease Control and Prevention. (2019). Complications of measles. Retrieved from 
https://www.cdc.gov/measles/symptoms/complications.html?CDC_AA_refVal=https\%3 A\%2F\%2Fwww.cdc.gov\%2Fmeasles $\% 2$ Fabout $\% 2$ Fcomplications.html

Centers for Disease Control and Prevention. (2020). Coronavirus Disease 2019 (COVID-19):

Older adults. Retrieved from https://www.cdc.gov/coronavirus/2019-ncov/need-extraprecautions/older-adults.html

Detoc, M., Bruel, S., Frappe, P., Tardy, B., Botelho-Nevers, E., \& Gagneux-Brunon, A. (2020). Intention to participate in a COVID-19 vaccine clinical trial and to get vaccinated against COVID-19 in France during the pandemic. Vaccine, 38, 7002-7006. https://doi.org/10.1016/j.vaccine.2020.09.041

Dodd, R., Cvejic, E., Bonner, C., Pickles, K., \& McCaffery, K. (2020). Willingness to vaccinate against COVID-19 in Australia. The Lancet Infectious Diseases. https://doi.org/10.1016/S1473-3099(20)30559-4

Dryhurst, S., Schneider, C. R., Kerr, J., Freeman, A. L. J., Recchia, G., van der Bles, A. M., ... van der Linden, S. (2020). Risk perceptions of COVID-19 around the world. Journal of Risk Research, 1-13. https://doi.org/10.1080/13669877.2020.1758193

Dubé, E., Laberge, C., Guay, M., Bramadat, P., Roy, R., \& Bettinger, J. A. (2013). Vaccine hesitancy: An overview. Human Vaccines \& Immunotherapeutics, 9(8), 1763-1773. https://doi.org/10.4161/hv.24657

Faasse, K., \& Newby, J. (2020). Public perceptions of COVID-19 in Australia: Perceived risk, knowledge, health-protective behaviors, and vaccine intentions. Frontiers in Psychology. https://doi.org/10.3389/fpsyg.2020.551004

Finnish Government. (2020a). Government, in cooperation with the President of the Republic, declares a state of emergency in Finland over coronavirus outbreak. Retrieved from https://valtioneuvosto.fi/en/-/10616/hallitus-totesi-suomen-olevan-poikkeusoloissakoronavirustilanteen-vuoksi 
Finnish Government. (2020b). Movement restrictions to Uusimaa - the Government decided on further measures to prevent the spread of the coronavirus epidemic. Retrieved from https://valtioneuvosto.fi/en/-/10616/uudellemaalle-liikkumisrajoituksia-hallitus-paattiuusista-lisatoimista-koronaepidemian-leviamisen-estamiseksi

Finnish Institute for Health and Welfare. (2020). Confirmed coronavirus cases (COVID-19) in Finland. Retrieved from https://experience.arcgis.com/experience/92e9bb33fac744c9a084381fc35aa3c7

Galasso, V., Pons, V., Profeta, P., Becher, M., Brouard, S., \& Foucault, M. (2020). Gender differences in COVID-19 attitudes and behavior: Panel evidence from eight countries. PNAS, 117(44), 27285-27291. https://doi.org/10.1073/pnas.2012520117

Glöckner, A., Dorrough, A., Wingen, T., \& Dohle, S. (2020). The perception of infection risks during the early and later outbreak of COVID-19 in Germany: Consequences and recommendations. PsyArXiv. Retrieved from https://psyarxiv.com/wdbgc/

Griffith, D. M., Sharma, G., Holliday, C. S., Enyia, O. K., Valliere, M., Semlow, A. R., ... Blumenthal, R. S. (2020). Men and COVID-19: A biopsychosocial approach to understanding sex differences in mortality and recommendations for practice and policy interventions. Preventive Chronic Disease, 17. https://doi.org/10.5888/pcd17.200247external icon

Harapan, H., Mudatsir, M., Yufika, A., Nawawi, Y., Wahyuniati, N., Anwar, S., ... Imrie, A. (2019). Community acceptance and willingness-to-pay for a hypothetical Zika vaccine: A cross-sectional study in Indonesia. Vaccine, 37(11), 1398-1406. https://doi.org/10.1016/j.vaccine.2019.01.062

Harper, C. A., Satchell, L. P., Fido, D., \& Latzman, R. D. (2020). Functional fear predicts public health complience in the COVID-19 P pandemic. International Journal of Mental Health and Addiction. https://doi.org/10.1007/s11469-020-00281-5 
Karafillakis, E., \& Larson, H. J. (2017). The benefit of the doubt or doubts over benefits? A systematic literature review of perceived risks of vaccines in European populations. Vaccine, 35(37), 4840-4850. https://doi.org/10.1016/j.vaccine.2017.07.061

Karlsson, L. C., Lewandowsky, S., Antfolk, J., Salo, P., Lindfelt, M., Oksanen, T., ... Soveri, A. (2019). The association between vaccination confidence, vaccination behavior, and willingness to recommend vaccines among Finnish healthcare workers. PLoS ONE, 14(10), 1-17. https://doi.org/10.1371/journal.pone.0224330

Karlsson, L., Tolvanen, M., Scheinin, N. M., Uusitupa, H. M., Korja, R., Ekholm, E., ... FinnBrain Birth Cohort Study Group. (2018). Cohort profile: The FinnBrain Birth Cohort Study (FinnBrain). International Journal of Epidemiology, 47(1), 15-16j. https://doi.org/https://doi.org/10.1093/ije/dyx173

Kwok, K. O., Li, K. K., Chan, H. H. H., Yi, Y. Y., Tang, A., Wei, W. I., \& Wong, S. Y. S. (2020). Community responses during early phase of COVID-19 epidemic, Hong Kong. Emerging Infectious Diseases, 26(7), 1575-1579. https://doi.org/10.3201/eid2607.200500.

Larson, H. J., Jarrett, C., Eckersberger, E., Smith, D. M. D., \& Paterson, P. (2014). Understanding vaccine hesitancy around vaccines and vaccination from a global perspective: A systematic review of published literature, 2007-2012. Vaccine, 32(19), 2150-2159. https://doi.org/10.1016/j.vaccine.2014.01.081

Loewenstein, G. F., Weber, E. U., Hsee, C. K., \& Welch, N. (2001). Risk as feelings. Psychological Bulletin, 127(2), 267-286. https://doi.org/10.1037/0033-2909.127.2.267

MacDonald, N. E., \& the SAGE Working Group on Vaccine Hesitancy. (2015). Vaccine hesitancy: Definition, scope and determinants. Vaccine, 33(34), 4161-4164. https://doi.org/10.1016/j.vaccine.2015.04.036 Malik, A. A., McFadden, S. M., Elharake, J., \& Omer, S. B. (2020). Determinants of 
COVID-19 vaccine acceptance in the US. EClinicalMedicine, 26. https://doi.org/10.1016/j.eclinm.2020.100495

Murphy, J., Vallières, F., Bentall, R. P., Shevlin, M., McBride, O., Hartman, T., ... Hyland, P. (2020). Preparing for a COVID-19 vaccine: Identifying and psychologically profiling those who are vaccine hesitant or resistant in two general population samples. PsyArXiv. Retrieved from https://psyarxiv.com/pev2b/

Neumann-Böhme, S., Varghese, N. E., Sabat, I., Barros, P. P., Brouwer, W., van Exel, J., ... Stargardt, T. (2020). Once we have it, will we use it? A European survey on willingness to be vaccinated against COVID-19. The European Journal of Health Economics, 21, 977-982. https://doi.org/10.1007/s10198-020-01208-6

Ophir, Y., \& Jamieson, K. H. (2018). Intentions to use a novel Zika vaccine: The effects of misbeliefs about the MMR vaccine and perceptions about Zika. Journal of Public Health, 40(4), e531-e537. https://doi.org/10.1093/pubmed/fdy042

Park, T., Ju, I., Ohs, J. E., \& Hinsley, A. (2020). Optimistic bias and preventive behavioral engagement in the context of COVID-19. Research in Social and Administrative Pharmacy. https://doi.org/10.1016/j.sapharm.2020.06.004

R Core Team. (2018). R: A language and environment for statistical computing. $R$ Foundation for Statistical Computing. Retrieved from https:/www.r-project.org/

Sarkanen, T., Alakuijala, A., Julkunen, I., \& Partinen, M. (2018). Narcolepsy associated with Pandemrix vaccine. Current Neurology and Neuroscience Reports, 18(43). https://doi.org/10.1007/s11910-018-0851-5

Schmid, P., Rauber, D., Betsch, C., Lidolt, G., \& Denker, M.-L. (2017). Barriers of influenza vaccination intention and behavior-A systematic review of influenza vaccine hesitancy, 2005-2016. PLoS ONE, 12(1), 1-46. https://doi.org/10.1371/journal.pone.0170550

Slovic, P., Finucane, M. L., Peters, E., \& MacGregor, D. G. (2004). Risk as analysis and risk 
as feeling: Some thoughts about affect, reason, risk and rationality. Risk Analysis, 24(2), 311-322. https://doi.org/10.1111/j.0272-4332.2004.00433.x

The COCONEL Group. (2020). A future vaccination campaign against COVID-19 at risk of vaccine hesitancy and politicisation. The Lancet Infectious Diseases, 20(7), 769-770. https://doi.org/10.1016/S1473-3099(20)30426-6

Thomson, A., Robinson, K., \& Vallée-Tourangeau, G. (2016). The 5As: A practical taxonomy for the determinants of vaccine uptake. Vaccine, 34(8), 1018-1024. https://doi.org/10.1016/j.vaccine.2015.11.065

Wang, Y., McKee, M., Torbica, A., \& Stuckler, D. (2019). Systematic literature review on the spread of health-related misinformation on social media. Social Science and Medicine, 240. https://doi.org/10.1016/j.socscimed.2019.112552

Ward, J. K., Alleaume, C., Peretti-watel, P., \& the COCONEL Group. (2020). The French public's attitudes to a future COVID-19 vaccine: The politicization of a public health issue. Social Science \& Medicine, 265. https://doi.org/10.1016/j.socscimed.2020.113414

Weinstein, N. D., Kwitel, A., Mccaul, K. D., Magnan, R. E., Gerrard, M., \& Gibbons, F. X. (2007). Risk perceptions: Assessment and relationship to influenza vaccination. Health Psychology, 26(2), 146-151. https://doi.org/10.1037/0278-6133.26.2.146

WHO. (2020a). WHO Director-General's opening remarks at the media briefing on COVID19 - 11 March 2020. Retrieved from https://www.who.int/dg/speeches/detail/whodirector-general-s-opening-remarks-at-the-media-briefing-on-covid-19---11-march-2020 WHO. (2020b). WHO Director-General's opening remarks at the media briefing on COVID19 - 3 March 2020. Retrieved from https:/www.who.int/dg/speeches/detail/whodirector-general-s-opening-remarks-at-the-media-briefing-on-covid-19---3-march2020?fbclid=IwAR2F5vbw2_Jd6GfaxlqJx4OttOy_QfSUayAfMLimhgBfPzRq5cLVnG $\mathrm{C} 5 \mathrm{x} 2 \mathrm{k}$ 
Wise, T., Zbozinek, T. D., Michelini, G., Hagan, C. C., \& Mobbs, D. (2020). Changes in risk perception and self-reported protective behaviour during the first week of the COVID19 pandemic in the United States. Royal Society Open Science, 7. https://doi.org/10.1098/rsos.200742 